\title{
A IDENTIFICAÇÃO E DOCUMENTAÇÃO DAS ESCOLAS PADRÃO Art Déco no Rio Grande do Sul
}

\author{
The identification and documentation of Art Déco standard schools in \\ Rio Grande do Sul
}

\author{
iD 9 \\ Lisiê Kremer Cabral \\ Universidade Federal de Pelotas, Pelotas, Rio Grande do Sul, Brasil \\ lisikcabral@yahoo.com.br \\ iD 0 \\ Ana Lúcia Costa de Oliveira \\ Universidade Federal de Pelotas, Pelotas, Rio Grande do Sul, Brasil \\ lucostoli@gmail.com \\ iD 0 \\ José Henrique Carlucio Cordeiro \\ Universidade Federal de Pelotas, Pelotas, Rio Grande do Sul, Brasil \\ joseccordeiro@yahoo.com.br
}

Resumo

As atividades escolares no Brasil, em seu princípio, eram exercidas em residências particulares ou instituições religiosas e, portanto, usufruíam de pouca infraestrutura. Com o decorrer dos anos e a valorização da educação pelo Estado, especialmente entre o final do século XIX até a década de 1920, começaram a ser construídos edifícios específicos para esta função. A partir de 1920, houve uma reestruturação do sistema escolar, buscando ampliar o acesso à educação. A partir dessas novas diretrizes, foram propostas melhorias nos programas e no ambiente escolar. O racionalismo das construções permitiu agilidade e economia nas obras, fazendo com que fossem propostas novas concepções para as escolas. Nesse interim o governo do Rio Grande do Sul criou um projeto padrão, a ser disseminado em diferentes localidades, com adaptações de acordo com o número de usuários. Com o objetivo de apresentar as instituições escolares Art Déco de projeto padrão no Rio Grande do Sul, este artigo contextualiza o cenário político-social em que essas construções foram idealizadas, junto à compilação de dados encontrados através de levantamentos e buscas em arquivo históricos, analisando de maneira mais aprofundada o material de duas escolas estaduais pertencentes a esse programa - Escola Cruzeiro do Sul, em São Lourenço do Sul/RS; Instituto Estadual de Educação Assis Brasil, em Pelotas/RS.

Palavras-chave: Arquitetura Art Déco. Escolas padrão. Patrimônio escolar. Preservação. 


\section{Abstract}

School activities in Brazil, in principle, were carried out in private homes or religious institutions and, therefore, presented little infrastructure. Over the years and the appreciation of education by the State, especially between the end of the 19th century and the 1920s, specific buildings for this function began to be constructed. From 1920 onwards, the federal government restructured the school system, seeking to expand access to education. With new guidelines, improvements were proposed in the programs and in the school environment, as well as the rationalism of the constructions allowed agility and economy in the constructions, making new concepts for schools proposed. The government of Rio Grande do Sul created a school standard project, to be disseminated in different locations, with adaptations according to the number of users. In order to show the Art Déco school institutions of standard design in the State, the political-social scenario in which these constructions were conceived will be contextualized, together with the compilation of data found through surveys and searches in historical archives, analyzing in more depth the material of two state schools belonging to this program - Escola Cruzeiro do Sul, in São Lourenço do Sul/RS; State Institute of Education Assis Brasil, in Pelotas / RS.

Keywords: Art Déco architecture. Standard schools. School heritage. Preservation.

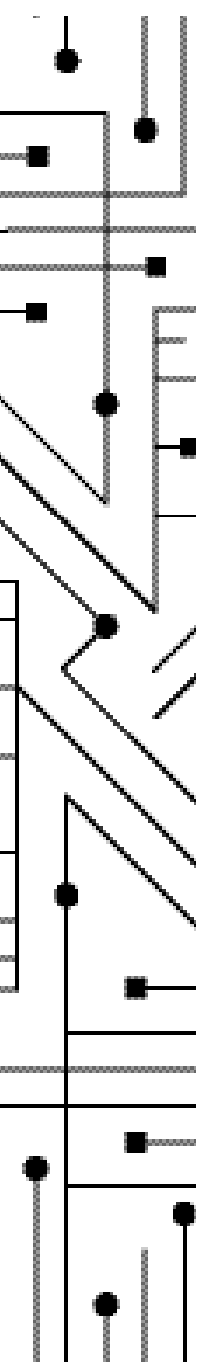




\section{Introdução}

Até o final do século XIX, as atividades escolares eram inseridas em edificações de forma improvisada, sendo a maioria de cunho privado e religioso, com pouco interesse por parte do poder público. Com o passar dos anos e a valorização da educação, os prédios escolares ganharam relevância e imponência, porém ainda não atendiam à demanda de alunos de forma satisfatória, pois somente a parte economicamente mais abastada da população tinha acesso ao ensino. O baixo número de escolas públicas, com espaços insatisfatórios, levou ao aumento do analfabetismo e, como consequência, a busca por novas estratégias para persuadir a matrícula e a permanência do aluno na escola, priorizando questões higiênicas e de conforto (FARIA FILHO, 1998; CARVALHO, 1989 apud DÓREA, 2000, p. 152).

Durante os anos do primeiro governo de Getúlio Vargas à frente da presidência da República (1930-1945), com a intenção de ampliar a rede de educação pública e torná-la acessível às classes de renda mais baixa, foram construídas novas escolas, como edificações modelo. No Rio Grande do Sul, nesta mesma época, foi implementado um projeto padrão para edificações escolares, com semelhanças compositivas e variações programáticas relativas ao número de alunos atendidos. O projeto padrão para escolas surge, portanto, durante um período de afirmação do modernismo no país.

Ao longo do período do Estado Novo (1937-1945), Vargas assume uma arquitetura monumental e moderna para as instituições públicas do país, através de expressões em Art Déco, de forma a evidenciar a modernização e o progresso planejado pelo governo brasileiro (SÁ, 2005 apud VIANA, 2011, p.81). Denominada por alguns autores como protomodernismo, essa manifestação artística sucedeu no Brasil a partir de 1920, dispondo de significativa relevância no estado do Rio Grande do Sul (RIO DE JANEIRO, 2001). Os prédios Art Déco das cidades de Porto Alegre e Pelotas possuem semelhanças construtivas, de forma a enfatizar os recuos e a marcações horizontais com uso de linhas retas (MONTAGNER, 2015). 
Nesse contexto de racionalização das construções, começaram a ser valorizadas questões de conforto ambiental, como iluminação natural e ventilação dos ambientes, junto com o emprego da estrutura independente em concreto armado. Isso vem a gerar uma arquitetura caracterizada pela pouca ornamentação e seguindo o novo conceito do racionalismo arquitetônico. Podem ser destacadas como particularidades do Art Déco a existência de pouca decoração, realce nas construções em esquinas, marcação de base, corpo e coroamento, presença de varandas e terraços (OLIVEIRA, 2008).

Este artigo se origina na dissertação de mestrado de Cabral (2020), "Arquitetura Art Déco nas escolas do Rio Grande do Sul no período do Estado Novo (19301950)", e tem por objetivos (i) apresentar o contexto histórico em que as escolas de projeto padrão Art Déco foram implementadas no Rio Grande do Sul e (ii) mostrar a apropriação dos usuários por essas instituições. Assim, pretende-se divulgar a história do patrimônio escolar riograndense, fomentando a pesquisa e proteção desses exemplares de caráter sociocultural.

\section{Metodologia}

Para atingir os objetivos deste trabalho propõem-se duas etapas metodológicas. A primeira consistiu em pesquisa bibliográfica a fim de embasar o contexto histórico em que as escolas de projeto padrão foram implementadas no estado gaúcho. A segunda foi composta pela investigação documental com visitas exploratórias para tratar da apropriação dos usuários às instituições estudadas.

Para a realização dessa segunda parte foram escolhidos dois exemplares das escolas estudadas, uma escola referente ao modelo de menor número de alunos atendidos e outra ao maior modelo. Os objetos de estudo escolhidos para este artigo foram a Escola Cruzeiro do Sul, localizada em São Lourenço do Sul/RS, para 250 alunos, e o Instituto Estadual de Educação Assis Brasil, situado em Pelotas/RS, para 750 alunos. 


\section{Desenvolvimento da Educação no Brasil}

Da época do Brasil colonial até o final do período imperial, as escolas eram implantadas de maneira improvisada, em edificações que eram adaptadas para o uso em questão, não levando em consideração aspectos de higiene e conforto de seus usuários. Conforme Cruz e Carvalho (2004), as instituições religiosas eram as responsáveis pela educação no país durante esse período, com pouca menção à pedagogia e à arquitetura.

Em consequência das mudanças nas relações do Estado com a sociedade, aliada ao desenvolvimento econômico, à expansão industrial e à urbanização, ocorridas nos séculos XIX e XX, a educação brasileira passou a ser tomada sob um novo ponto de vista. A partir daí o ensino é compreendido como mecanismo de inserção coletiva e propulsor do progresso (BENCOSTTA, 2005; FARIA FILHO, 1998).

Na Primeira República houve a iniciativa das primeiras construções unicamente 5 para o uso escolar. Apresentando majoritariamente arquitetura neoclássica, essas escolas apresentavam-se em edifícios monumentais, com rígida simetria, elevado pé direito, acesso principal destacado com escadarias, diferenciando-se do seu entorno (KOWALTOWSKI, 2013). De acordo com Oliveira (2007), o projeto para edifícios escolares era concebido entorno de um eixo de simetria, normalmente com circulações em $\mathrm{U}$ ou $\mathrm{H}$, o que possibilitava a formação de um pátio interno.

Essas primeiras escolas foram denominadas Escolas Normais, quando necessário um programa mais enxuto, e Grupos Escolares, para uma demanda maior de alunos. A proposta para Escolas Normais, usualmente em dois pavimentos, contava apenas com salas de aula, separadas por sexos, e espaços administrativos, já os Grupos Escolares tinham ainda biblioteca, anfiteatros e laboratórios. A configuração desses ambientes levava em consideração as condições de luz e ar estabelecidas nas normativas do Código Sanitário de 1894 e eram dispostas através de planta tipo que era reproduzida em diferentes localidades, com pequenas alterações conforme necessário (KOWALTOWSKI, 2013). 
No período de 1920-30, instaurou-se o movimento Escola Nova que, através de reformas no ensino, respaldava o acesso à escola e à educação por parte de toda população (OLIVEIRA, 2007). Fizeram parte deste movimento os educadores Fernando de Azevedo, Manuel Bergstrom Lourenço Filho e Anísio Spínola Teixeira. O grupo tinha como objetivo a reformulação do ensino, com educação integral, colocando a criança no centro do processo ensino-aprendizagem (BUFFA, 2002; NASCIMENTO, 2012).

Durante a década de 1930, no governo de Getúlio Vargas, houve a reformulação da educação através de edificações modelo que possuíam linhas geométricas e características Art Déco, uma arquitetura com conceito econômico, eficiente e funcional (SEGAWA, 1997).

Percebe-se que além de prover economia e agilidade às construções, as escolas de projeto padrão se tornam símbolo e agrupam a marca cultural de uma comunidade. Pode-se afirmar que a padronização dos prédios escolares potencializa o apelo à identidade e a um novo anseio cultural, relacionando o desenvolvimento e progresso, a partir da edificação escolar, ao governo da época (ESCOLANO; FRAGO, 2001; KOWALTOWSKI, 2013).

No estado de São Paulo, a Comissão de Prédios Escolares, em 1936, desenvolveu um trabalho intitulado "Novos prédios para grupos escolares", com o intuito de orientar os novos projetos para os centros educacionais. Nesse documento eram estabelecidas concepções arquitetônicas simples com baixo custo, de estrutura em concreto armado, em que a forma deveria adaptar-se ao uso. O novo plano de necessidades contava com salas odontológicas, médicas, espaço para educador sanitário, salas para leitura, ginásio e auditório. (OLIVEIRA, 2007).

Algumas dessas edificações escolares paulistas ${ }^{1}$, projetadas por José Maria da Silva Neves na segunda metade da década de 30, que seguiram as recomendações da Comissão de Prédios Escolares, foram protegidas em 2018 por serem consideradas

\footnotetext{
1 Edificações tombadas a partir da resolução no 17 realizada pelo Conselho Municipal de Preservação
} do Patrimônio Histórico, Cultural e Ambiental da cidade de São Paulo - CONPRESP, em fevereiro de 2018. 
símbolos do início do modernismo, do uso de novas técnicas construtivas e do novo programa pedagógico.

\section{Desenvolvimento das escolas padrão no Rio Grande do Sul}

Em 1896, João Abbot, secretário do interior e exterior do Rio Grande do Sul, considerava que para iniciar a reforma no ensino público, de maneira efetiva, o ambiente escolar deveria oferecer entusiasmo e incentivo aos alunos através de bons professores e edificações adequadas ao uso, com ambientes iluminados e amplos (LUCHESE, 2012).

Segundo Scherer (2015), a criação dos colégios elementares, em 1909, inaugurou no Estado do Rio Grande do Sul um modelo de escola alinhado com a ideologia política da época, com a consequente expansão do atendimento do ensino primário pelo poder público. As instalações dessas edificações eram oferecidas pelos municípios, em função de demanda e oferta de alunos.

Em 1928, foi promovido um concurso para projeto de edificações escolares, com diretrizes pré-estabelecidas, indicando a demanda atendida pelas instituições. Era prevista a variação das dimensões das escolas conforme o número de alunos atendidos por elas - entre 250, 300, 350, 400, 450, 500, 550, 600, 800 e 1.000 alunos. Deveriam ser planejados espaços para sala de espera, administração, biblioteca, museu didático, sala para trabalhos manuais, sala para consultório médico, sala para atendimento odontológico, salão para solenidades e banheiro. O projeto precisaria ser idealizado de forma a adaptar-se a possíveis ampliações, por esse motivo teria que contar com paredes não portantes para possibilitar futuras reformas (ERMEL, 2017).

No final dos anos 30 , com a crise política da época tendo em vista a $2^{\circ}$ Guerra Mundial e o elevado número de imigrantes no estado, J.P. Coelho de Souza, então Secretário de Educação do Rio Grande do Sul, implementou uma rede de escola públicas com objetivo de nacionalizar os imigrantes e seus descendentes (WERLE, 
2014). Para atender a demanda de ensino com qualidade e princípios nacionalistas, seriam construídos 49 prédios escolares com capacidade variável entre 200 e 750 alunos, em zona urbana com tipologia padrão (SOUZA, 1941).

Por se tratar de projeto padrão, com arquitetura Art Déco, as obras admitiam uma rápida execução com baixo custo, propiciando, mesmo em diferentes localizações, semelhanças formais. As características desta arquitetura são volumes geométricos, enfatizando da esquina, telhado cerâmico na cobertura, platibanda cega com formas retas, pouca ornamentação, delimitação horizontal acima das esquadrias. A linguagem preconizava novos métodos, programas e técnicas construtivas para otimizar a construção de caráter progressista (COREIA, 2010).

Como exemplo desse período, podem ser citadas no estado do Rio Grande do Sul as seguintes instituições: Escola Estadual de Educação Cruzeiro do Sul, localizada, São Lourenço do Sul, para 250 alunos; Escola Estadual de Ensino Fundamental Marques de Souza, São José do Norte, para 200 alunos; Escola; Instituto Estadual de Educação Gomes Jardim, Guaíba, para 350 alunos, Escola Estadual de Ensino Fundamental Joaquim Caetano da Silva, Jaguarão, para 500 alunos; Instituo Estadual de Educação Assis Brasil, Pelotas, para 750 alunos (Figura 01).

Figura 1 - Escolas com projeto padrão Art Déco, Rio Grande do Sul.
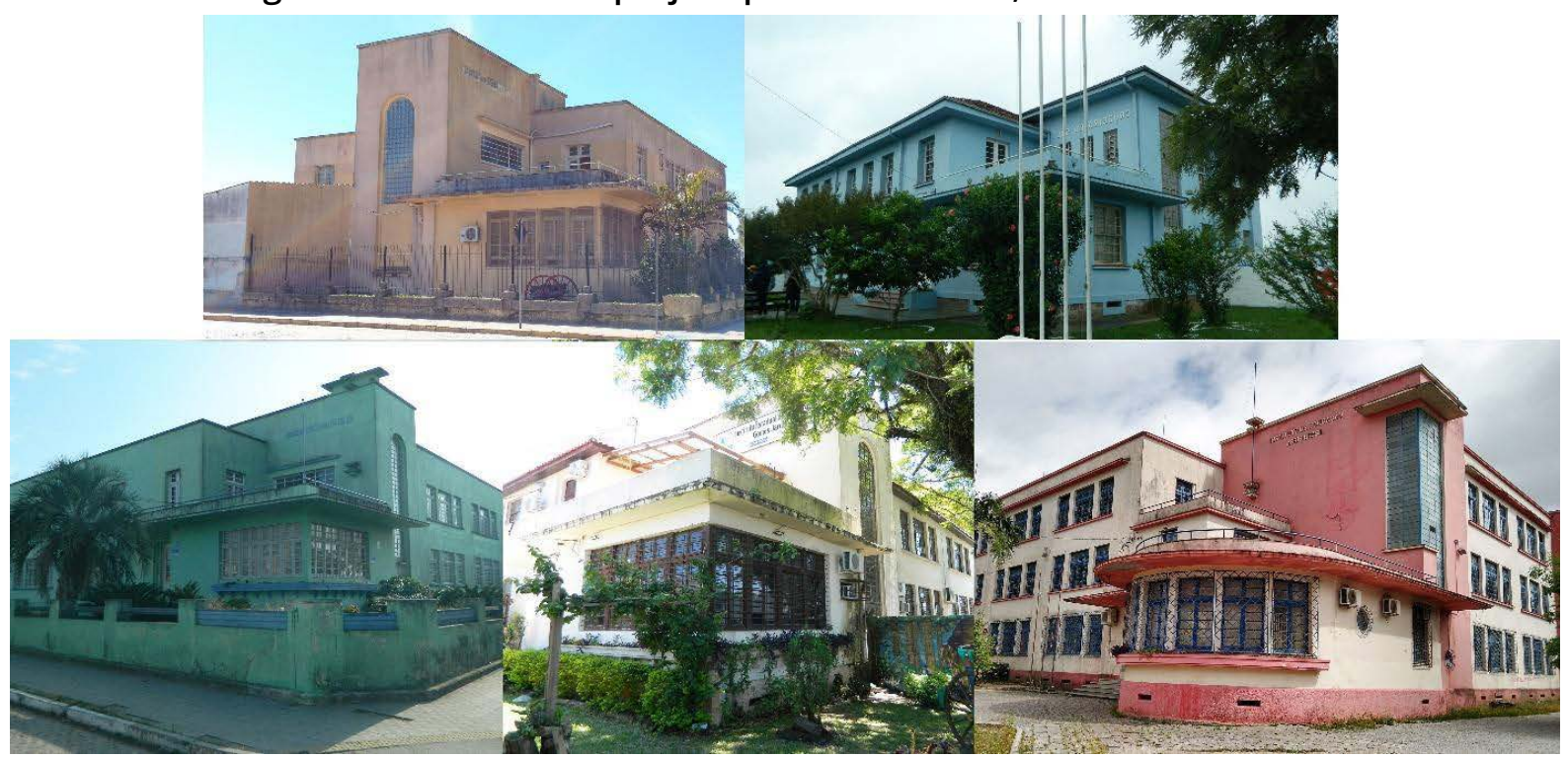

Fonte: Acervo Lisiê Kremer Cabral. 


\section{Identificação e Documentação}

A importância dos bens históricos e arquitetônicos da sociedade brasileira é reforçada pelo seu reconhecimento e catalogação. Portanto, cadastrar determinados bens de valor material e imaterial como os projetos das escolas padrão no Rio Grande do Sul com a intenção de impulsionar ações que visam gerar critérios e motivos para sua preservação é de valor para este estudo. Aos historiadores, arquitetos urbanistas, antropólogos, sociólogos e outras especializações do conhecimento é de fundamental relevância pesquisas que mapeiam nosso acervo arquitetônico, que sirvam de base para seus estudos.

A imagem, retratada em fotografias, pinturas, discursos, rituais, entre outros, é percebida através do estudo de instrumentos e materiais acessíveis ao pesquisador, os quais são interpretados, possibilitando, assim, a construção de um ponto de vista sobre os fatos históricos (PESAVENTO, 2012). Uma vez que o historiador não se fez presente durante um dado acontecimento no passado, sua análise e interpretação acontecerão a partir de novos valores e significados de acordo com a percepção das reproduções.

O entendimento do pesquisador sobre a representação de um artefato histórico é o que dá sentido hoje a um fato não presenciado no passado. A narrativa histórica é construída por meio da conexão entres os fatos, através de um enfoque analítico, tecendo uma linha hipotética. No momento em que é atribuído a uma ilustração valores de relevância e aceitabilidade social pode-se perceber sua expressividade, de forma a servir de instrumento de influência social (PESAVENTO, 2012).

A partir da combinação de pesquisa online, bibliográfica e histórica, de documentos, plantas e materiais na Secretaria de Obras Públicas do Rio Grande do Sul, Arquivo Histórico do Rio Grande do Sul, Biblioteca Estadual, Secretaria de Educação do Rio Grande do Sul, como também, nos acervos das escolas, foram identificadas 39 construções escolares de projeto padrão Art Déco (CABRAL, 2020). 
Pode-se averiguar, a partir do material gráfico coletado (Figura 02), que o autor desses projetos foi o engenheiro João Baptista Pianca (CABRAL, 2020). Formado pela Escola de Engenharia de Porto Alegre em 1915, Pianca começou a trabalhar na Secretaria de Obras Públicas de Porto Alegre no ano de 1919, idealizando projetos escolares para todo o estado do Rio Grande do Sul (WEIMER, 2004).

Figura 2- Plantas de $1^{\circ}$ e $2^{\circ}$ pavimentos para um colégio com projeto padrão de 250 alunos, Rio Grande do Sul.

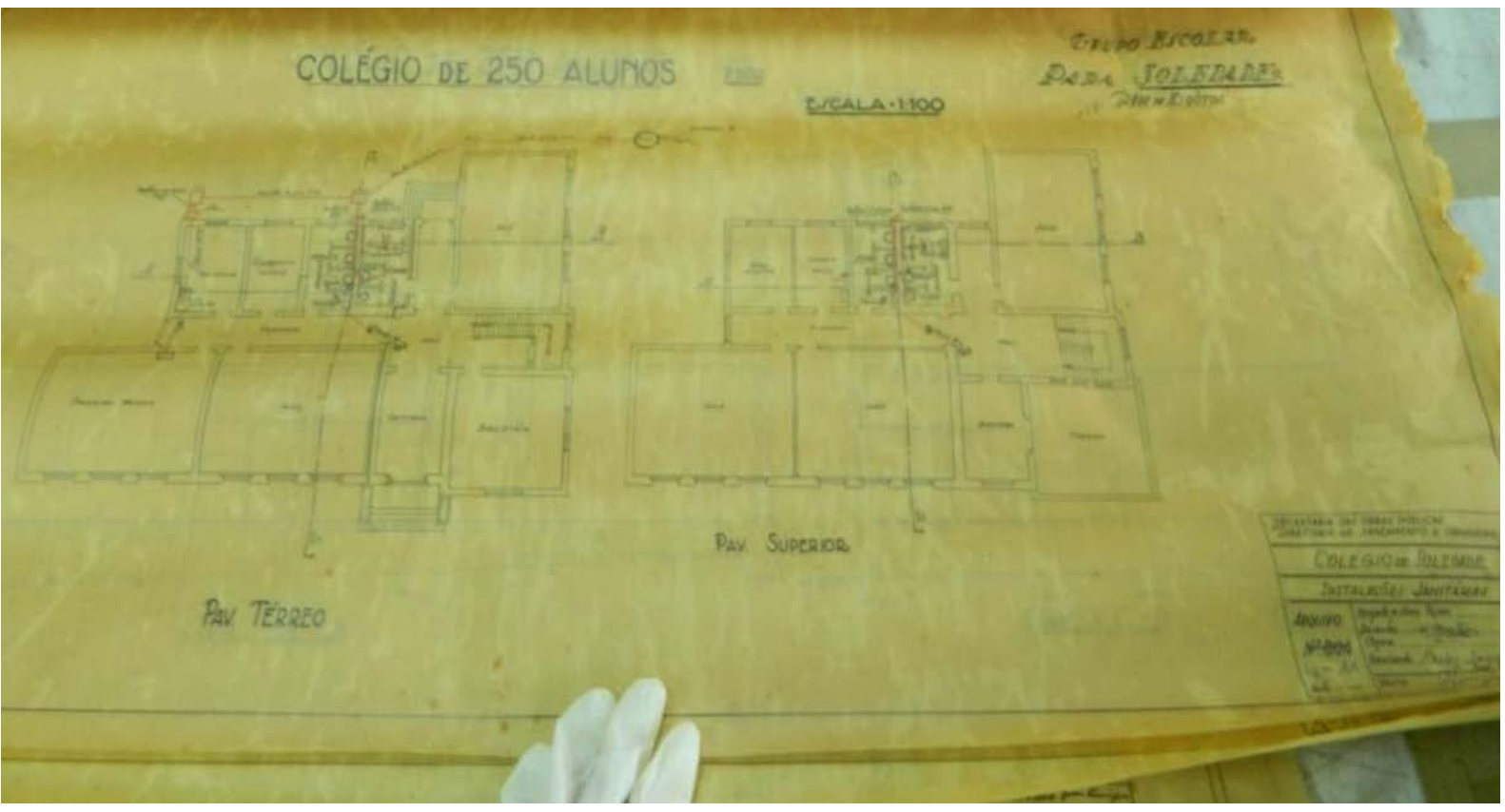

Fonte: Acervo da Mapoteca da Diretoria de Obras Públicas/RS. Acesso em: 2018.

\section{Instituto Estadual de Educação Assis Brasil - 750 alunos}

Em 1929, com a renovação dos métodos pedagógicos e o aumento do número de solicitações de matrículas na rede de educação pública, foi fundada a Escola Complementar de Pelotas. Após as reestruturações do ensino no estado gaúcho, a escola foi transferida a uma nova edificação (figura 03), localizada em um lote de esquina no centro da cidade, projetada pelo engenheiro João Baptista Pianca e construída pela construtora Haessler \& Woebcke. 
Sob o nome de Instituto Estadual de Educação Assis Brasil, o novo prédio foi inaugurado em 9 de março de 1942, contando com a presença de autoridades da época, como o intendente municipal Dr. João Py Crespo, o secretário do interior Dr. Osvaldo Aranha. Dividida em três pavimentos, contemplando jardim de infância, ensino primário, auditório, biblioteca, laboratórios, museu, salas de aula em forma de anfiteatro e terraço para hasteamento da bandeira nacional. No ano de inauguração a escola contou com 90 alunos matriculados (IEEAB, 2004, p.1).

\section{Figura 3 - Fachada Instituto Estadual de Educação Assis Brasil.}

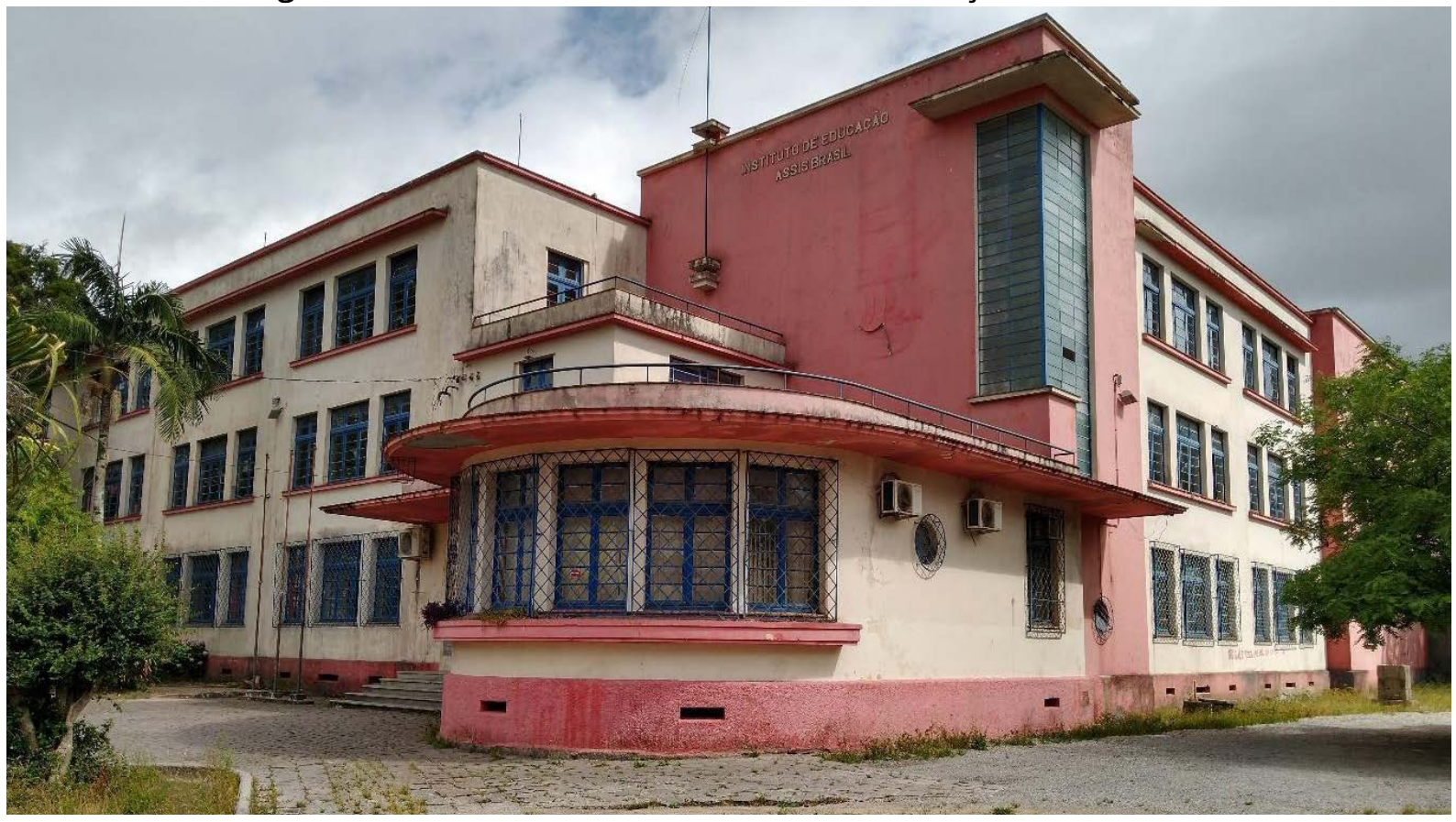

Fonte: Acervo Lisiê Kremer Cabral (2020).

Como forma de registrar e documentar a história da instituição, assim como divulgar as atividades escolares, em 1978, foi publicada a revista Informe IEAB, sendo encontrado até o quarto exemplar, datando de 1979, no acervo da biblioteca do Instituto Assis Brasil (CABRAL; OLIVEIRA, 2018).

O cinquentenário do educandário foi comemorado em 1979 (Figura 04), com expressiva comemoração pelos escolares, pais e mestres, como também e pela sociedade em geral. Foram realizados desfiles com a banda marcial, carros alegóricos e alunos pelas principais ruas de Pelotas/RS. Para celebração, a instituição adotou o 
verbete "Ontem, hoje e sempre pela educação" (IEEAB, 1979, p.1). O Instituto Assis Brasil destacava-se à época pelo porte da edificação, atendimento em três turnos, pela quantidade de alunos matriculados, qualidade do ensino e pelo vínculo social, salienta-se a colaboração promovida pelo círculo de pais e mestres (IEEAB, 1980).

Figura 4 - Caderno de comemoração do Jubileu (E); Carta do $20^{\circ}$ aniversário da instituição (D).

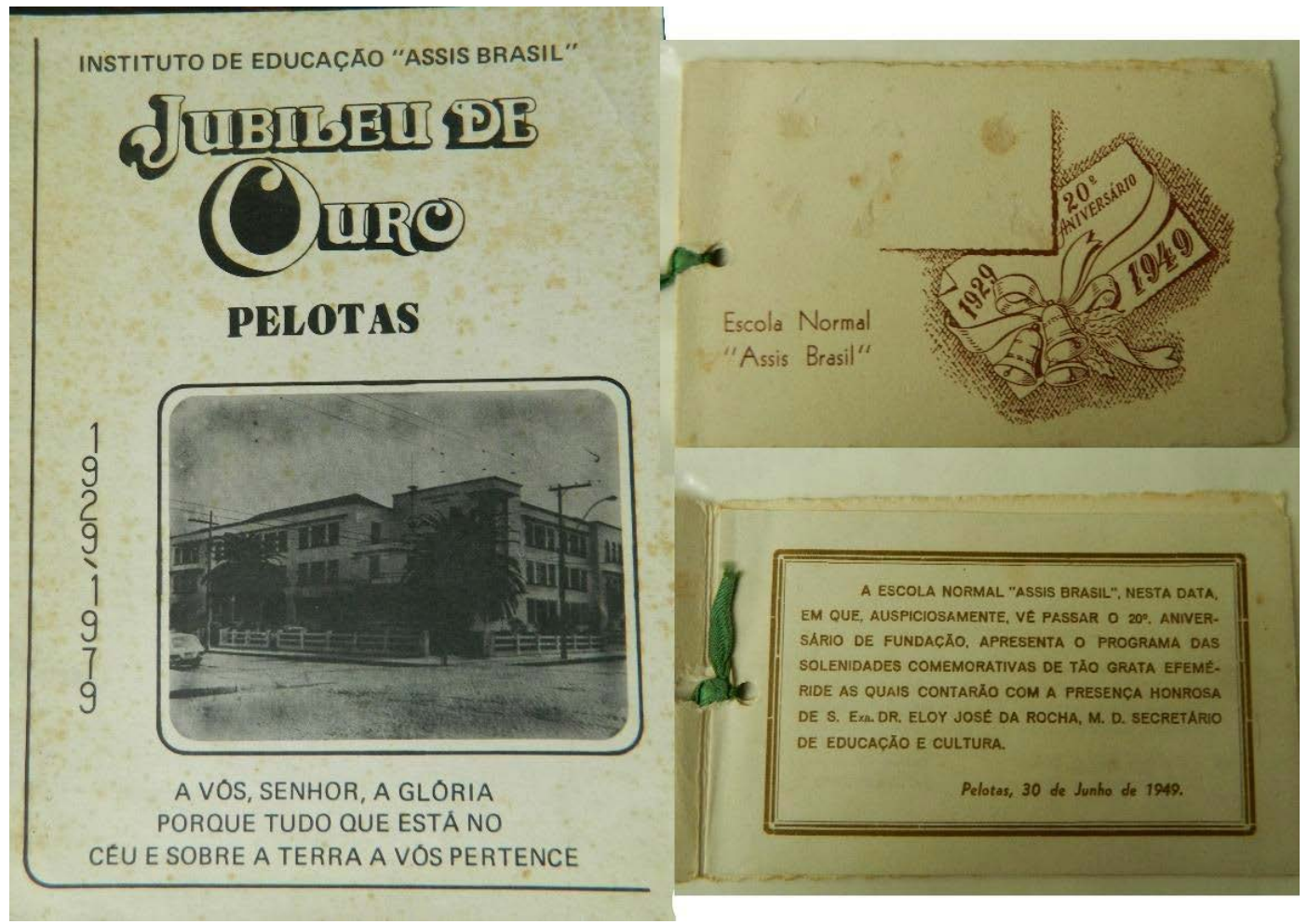

Fonte: Acervo Biblioteca do Instituto Assis Brasil (Acesso em: 2018).

O acervo pertencente à biblioteca da escola, contém diversos recortes de jornais, entre eles reportagens sobre professores e alunos que se destacaram no meio esportivo, artístico e social, lembranças e cadernos comemorativos dos aniversários da instituição, revistas como o Informe IEAB, boletins informativos, imagens antigas do prédio. No ano de 2007, foi lançado o livro "Instituto de Educação Assis Brasil: entre a memória e a história 1929-2006" com intuito de divulgar e valorizar a memória e a história coletiva são apresentados relatos dos membros pertencentes à instituição (AMARAL; AMARAL, 2007). 


\section{Escola Estadual de Educação Cruzeiro do Sul - 250 alunos}

Em 1926, foi instituído, na cidade de São Lourenço do Sul/RS, o Grupo Escolar São Lourenço do Sul. Essa instituição já ocupou três diferentes edificações antes de fixar-se no atual prédio (HAMMES, 2010) que foi projetado especificamente para o uso escolar, atendendo aos novos preceitos pedagógicos da época. A construção (figura 05), coordenada por Julio Besozzi, foi inaugurada em maio de 1948 e faz parte de um projeto padrão de arquitetura Art Déco, tendo capacidade para atender 250 alunos (CABRAL; CORDEIRO; OLIVEIRA, 2019).

Figura 5 - Fachada Instituto Estadual de Educação Cruzeiro do Sul.

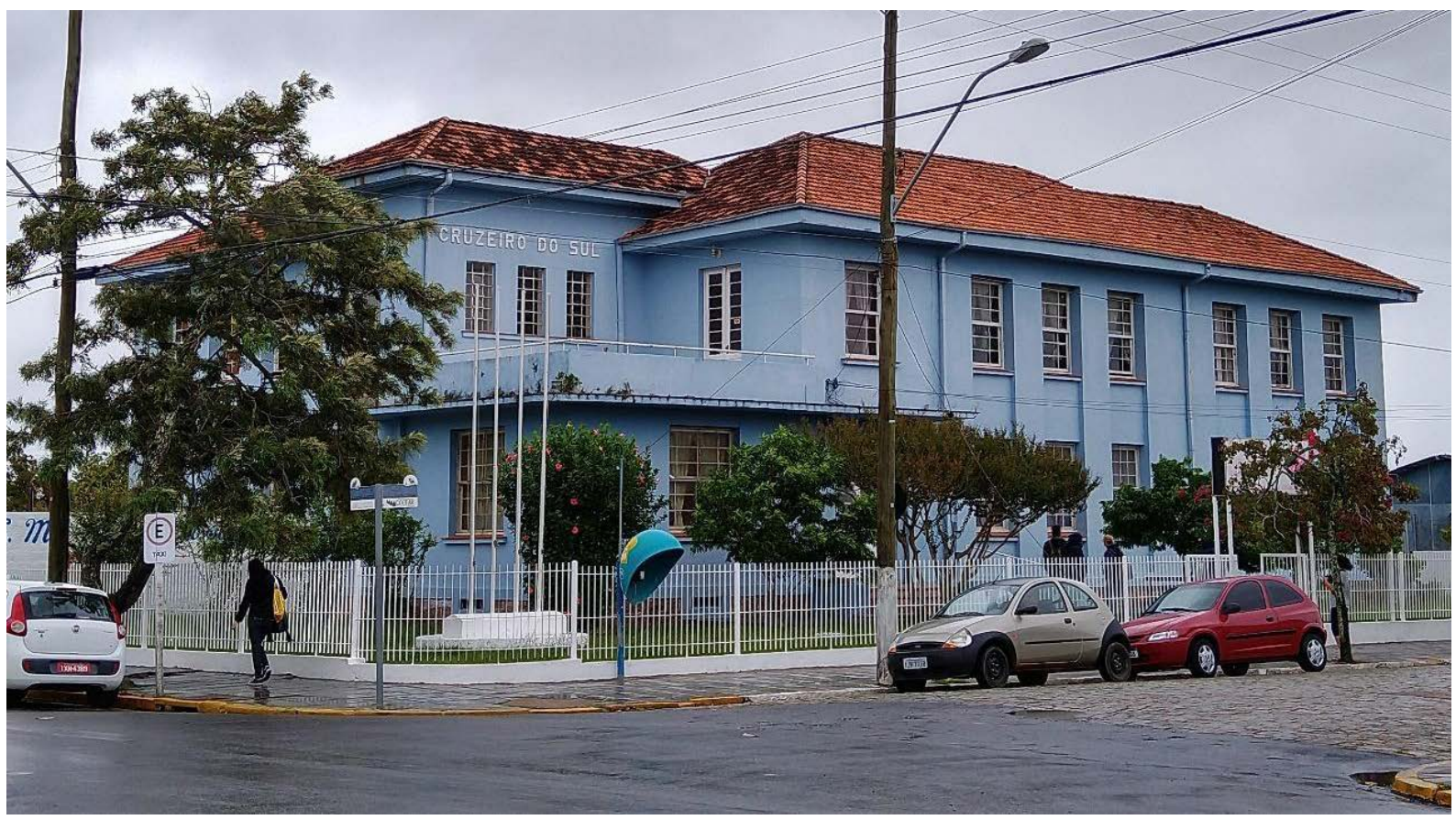

Fonte: Acervo Lisiê Kremer Cabral (2019).

No programa da escola estavam previstas salas de aula, sala para trabalhos manuais, biblioteca, gabinete médico e dentário, museu didático. Atualmente existem, aos fundos do terreno, novos ambientes para atender um maior número de alunos (CABRAL; CORDEIRO; OLIVEIRA, 2019). A instituição encontra-se em uma área central da cidade, em frente à praça principal, sendo reconhecida pela população pela 
sua arquitetura, porte e presença de novos elementos construtivos como o terraço (HAMMES, 2010).

O apreço da comunidade local pela escola pode ser percebido através de eventos comemorativos que ocorreram ao longo da história da instituição. Para festejar os 25 anos do educandário, no ano de 1951, houve uma celebração que contou com passeata de alunos e ex-alunos e a presença de membros importantes da comunidade (HAMMES, 2010). Em 1988, ocorreram desfiles e momentos cívicos enaltecendo a semana da pátria e os costumes nacionalistas, conforme recortes de jornal encontrados no acervo da escola.

O Jornal Correio da Lagoa, em abril de 1989, relata sobre o evento em comemoração ao $63^{\circ}$ aniversário do educandário, seriam propostas exposições, momentos cívicos (Figura 06) e missa na Igreja Nossa Senhora de Fátima.

Figura 6 - Desfile do Grupo Escolar Cruzeiro do Sul, no ano de 1953.

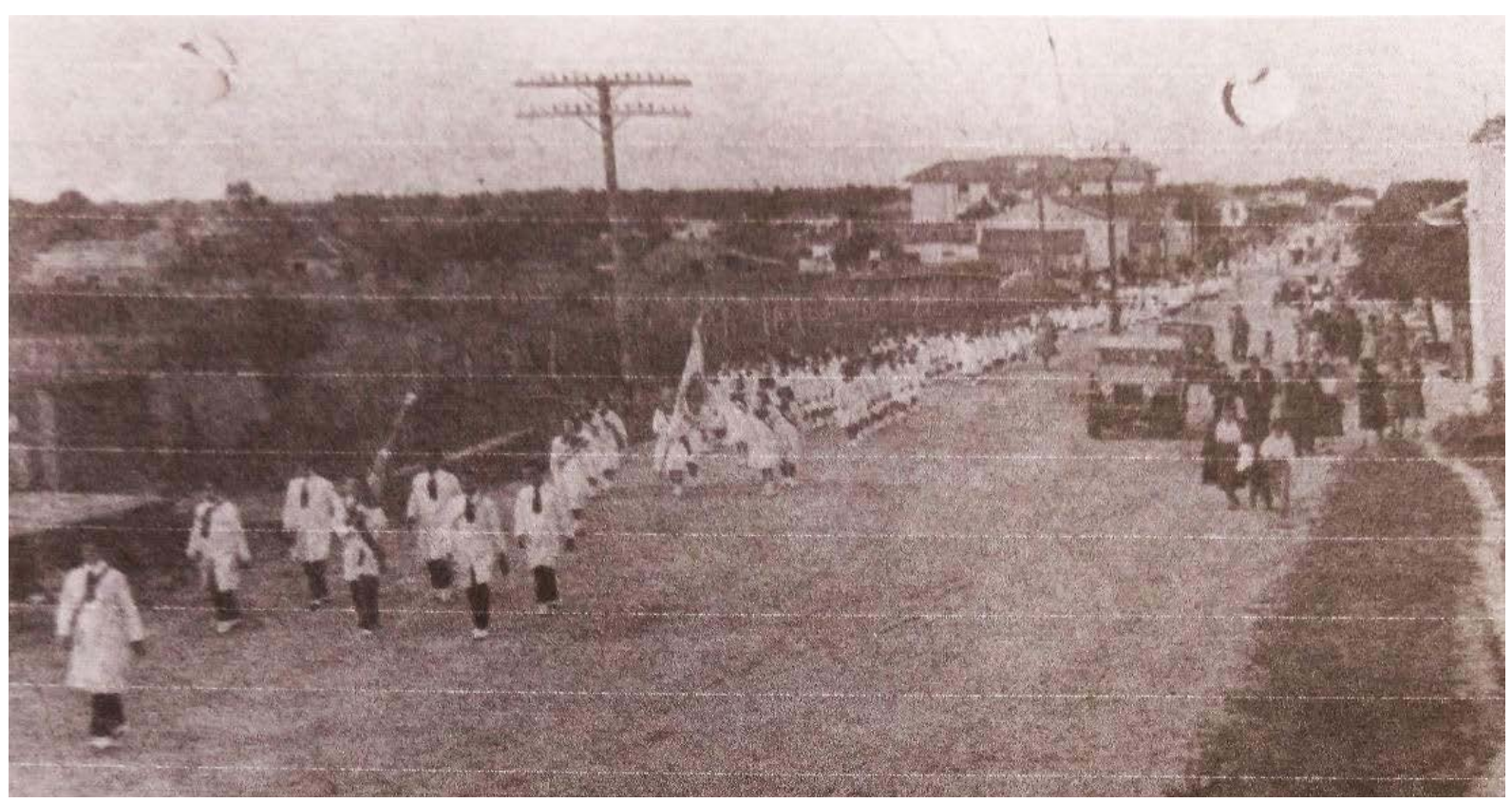

Fonte: Acervo da Escola Cruzeiro do Sul (Acesso em: 2019).

A escola possui um acervo que abrange Atas de presença, documentos, plantas de projetos, fotografias do prédio e de eventos comemorativos, recortes de jornal com notícias sobre a escola. No acesso principal da escola estavam expostas, em um 
mural, fotografias antigas com o título "A escola e o tempo..." junto a um informativo sobre o histórico da escola. No ano de 2016, foi publicado o livro "Escola Cruzeiro do Sul: 90 anos de história" com a intenção de rememorar e conservar as vivências culturais estabelecidas pela comunidade escolar, a obra apresenta poesias e relatos de professores, pais, alunos, ex-alunos e demais membros da sociedade lourenciana (DROSE, 2016).

\section{Conclusão}

As edificações escolares Art Déco no Rio Grande do Sul foram implementadas durante os anos de 1930-1950, período não presenciado pelos pesquisadores, logo a consolidação desse conteúdo foi realizada por meio de leituras de representações antigas, seja de cunho bibliográfico ou documental, e conexões entre as fontes acessadas. Observa-se que há a construção de uma nova compreensão sobre a finalidade para a qual essas instituições foram construídas. Quando reconhecidas as circunstâncias que originaram os prédios escolares - implementação de um novo método de ensino, política de nacionalização dos imigrantes e a nova linguagem arquitetônica - legitimam-se os códigos e símbolos que essas edificações possuem e a sua importância como instrumento de representação do governo da época e de influência social.

O projeto padrão no ambiente escolar é consequência das práticas de reprodução das edificações escolares do início do século $X X$, para atender com economia e agilidade uma demanda maior de alunos. O projeto padrão das escolas Art Déco do Rio Grande do Sul foi uma ferramenta para a disseminação da educação pelo estado, aliada às políticas nacionalistas de Vargas, de forma otimizada.

Através de um padrão projetual as edificações escolares, principalmente nos casos apresentados neste trabalho, tornam-se marcos de fácil identificação constituindo parte da imagem da comunidade local. Apresenta-se, assim, a eficiência 
da escola de arquitetura padronizada para tornar-se referência de identidade cultural para a sociedade.

Foi possível observar que as instituições com seu acervo histórico preservado, exposto ou de fácil acesso à comunidade escolar, tornam-se mais valorizadas e, consequentemente, preservadas. As duas edificações que constituíram os estudos de caso são exemplo e demonstram os reflexos dessas ações. Pode-se identificar o cuidado em que os documentos são guardados, estabelecendo uma conexão entre a sociedade e o prédio. $\mathrm{O}$ apreço com as instituições permite uma zeladoria que reforça as lembranças e rememorações existentes.

Através do acervo histórico, documental e bibliográfico, foi possível elucidar o contexto em que as edificações com projeto padrão foram idealizadas. Essas ações têm como intuito revelar questões de caráter político-social, divulgando o patrimônio escolar, salvaguardado a trajetória educacional do estado gaúcho e do país. 


\title{
REFERÊNCIAS
}

\begin{abstract}
AMARAL, L. do Giana; AMARAL, L. do Gladys. Instituto de Educação Assis Brasil: entre a memória e a história 1929-2006. Pelotas: Seiva, 2007. 183 p.
\end{abstract}

BENCOSTTA, Marcus L. A. Arquitetura e Espaço Escolar: o exemplo dos primeiros grupos escolares de Curitiba (1903-1928). In: BENCOSTTA, Marcus L. A. (org.) História da Educação, Arquitetura e Espaço Escolar. $1^{\text {a }}$ ed. São Paulo: Cortez Editora, 2005, p. 95-140.

BUFFA, Ester; PINTO, Gelson P. Arquitetura e Educação: organização do espaço e propostas pedagógicas dos grupos escolares paulistas 1893-1971. São Paulo: Universidade Federal de São Carlos, 2002. 174 p.

CABRAL, K. Lisiê. Arquitetura Art Déco nas escolas do Rio Grande do Sul no período do Estado Novo (1930-1950). 2020. 207 f. Dissertação (Mestrado em arquitetura) - Universidade Federal de Pelotas, PROGRAU, Pelotas, 2020. No Prelo.

CABRAL, K. Lisiê. CORDEIRO, C. José Henrique; OLIVEIRA, C. de Ana Lúcia. Arquitetura escolar e memória social: A Escola Cruzeiro do Sul, São Lourenço do Sul (RS). $11^{\circ}$ Mestres e Conselheiros. Belo Horizonte, 2019. 10 p. Disponível em: https://even3.blob.core.windows.net/processos/fee2ee215cf046c6a536.pdf.

CABRAL, K. Lisiê; OLIVEIRA, C. de Ana Lúcia. O patrimônio escolar protomoderno - Instituto Estadual de Educação Assis Brasil - 1942, na cidade de Pelotas/RS. II Simpósio Científico do ICOMOS Brasil. Belo Horizonte, 2018. 13 p. Disponível em: https://drive.google.com/drive/folders/18IKaMkYyzkB43jNVyFsBmcQYXN2g4a6e.

CORREIA, Telma B. O Art Déco na Arquitetura Brasileira. Revista UFG, Dossiê Art Déco, Ano XII n8, Goiás, 2010. 5 p. Disponível em: https://www.revistas.ufg.br/ revistaufg/article/view/48295/23636. Acesso em: Maio, 2018.

DÓREA. Célia R. D. Anísio Teixeira e a Arquitetura Escolar: Planejando escolas, construindo sonhos. Revista da FAEEBA. $n^{\circ} 13$. Ibicit - Biblioteca Virtual Anísio Teixeira. Salvador, 2000. p.151-160. Disponível em: http://www.bvanisioteixeira.ufba. br/artigos/dorea.html. Acesso: jun. 2020. 
DROSE, Cleia. Escola cruzeiro do Sul: 90 anos de história. São Lourenço do Sul: Pragmatha, 2016.

ERMEL, Tatiane F. Arquitetura escolar e patrimônio histórico-educativo: os edifícios para a escola primária pública no Rio Grande do Sul (1907-1928). 2017. 343 f. Tese (Doutorado em Educação). PUCRS, Porto Alegre, 2017. Disponível em: http:// tede2.pucrs.br/tede2/handle/tede/7337\#preview-link0. Acesso em: Maio, 2018.

ESCOLANO, Austín; FRAGO, Antonio. Arquitetura como programa: espaço escola e currículo. Rio de Janeiro: DP\&A. 2. Ed. 2001. 36 p.

FARIA FILHO, Luciano Mendes de. O espaço escolar como objeto da história da educação: algumas reflexões. Rev. Fac. Educ., São Paulo, v. 24, n. 1, p. 141-159, Jan, 1998. Disponível em: http://www.scielo.br/scielo.php?script=sci_arttext\&pid=S010225551998000100010\&lng=en\&nrm=iso. Acesso em: Maio de 2020. https://doi. org/10.1590/S0102-25551998000100010.

HAMMES, L. Edilberto. São Lourenço do Sul, Radiografia de um Município, das origens ao ano 2000. São Leopoldo: Studio Zeus, volume 2, 2010.

IEEAB. Documento redigido pela diretora Yeda da Silva Porto. Biblioteca do IEEAB Pelotas: 1980.

IEEAB. Informe IEAB. Ano II, n.3. Biblioteca do IEEAB. Pelotas: 1979.

IEEAB. Histório resumido do Instituto Estadual de Educação Assis Brasil $\mathbf{7 5}^{\circ}$ aniversário. 4 páginas. Biblioteca do IEEAB. Pelotas: 2004.

KOWALTOWSKI, Doris C.C.K. Arquitetura Escolar: o projeto do ambiente de ensino. São Paulo: Oficina de textos. $1^{a}$ reimpressão, 2013. 272 p.

LUCHESE. Ticiane A.; KREUTZ, Lúcio. Das escolas de improviso as escolas planejadas: um olhar sobre os espaços escolares da região colonial italiana, Rio Grande do Sul. Revista brasileira de educação. vol.12, nº 2 (29). São Paulo, 2012. p. 45-76. Disponível em: http://eduem.uem.br/ojs/index.php/rbhe/article/viewFile/38787/20316. Acesso em: Maio, 2018. 
MONTAGNER, Beatriz C. Arquitetura Moderna em Pelotas, 1950- 1980. 2015. $334 \mathrm{f}$. Dissertação (Mestrado em arquitetura) - Universidade Federal de Pelotas, PROGRAU, Pelotas, 2015. Disponível em: http://prograu.ufpel.edu.br/uploads/biblioteca. Acesso em: Março, 2017.

NASCIMENTO, Mario Fernando P. Arquitetura para a educação: a contribuição do espaço para a formação do estudante. 2012. 154 f. Dissertação (Mestrado em arquitetura) - Universidade de São Paulo, São Paulo, 2012. Disponível em: http:// www.teses.usp.br/teses/disponiveis/16/16133/tde-19062012-122428/pt-br.php Acesso em: Abril, 2018.

OLIVEIRA, Marcel S. G. Arquitetura em São Paulo na Era Vargas. O art déco e a arquitetura fascista nos edifícios públicos (1930-45). 2008. 139 f. Dissertação (Mestrado em arquitetura) - Universidade de São Paulo, 2008. Disponível em: https:// teses.usp.br/teses/disponiveis/16/16133/tde-16032010-093020/publico/Arquitetura em_Sao_Paulo_na_Era_Vargas.pdf. Acesso em: Maio, 2019.

OLIVEIRA, Fabiana V. Arquitetura escolar paulista nos anos 30. 2007. $140 \mathrm{f}$. Dissertação (Mestrado em arquitetura) - Universidade de São Paulo, São Paulo, 2007. Disponível em: http://www.teses.usp.br/teses/disponiveis/16/16133/tde-20052010152808/pt-br.php. Acesso em: Abril, 2018.

PESAVENTO, J. Sandra. História \& história cultural. Belo Horizonte: Editora Autêntica LTDA, 3. ed, 2012. 132 p.

RIO DE JANEIRO. Prefeitura Municipal do Rio de Janeiro. Art Deco no Rio de Janeiro. Rio de Janeiro: Casa da Palavra, 3. ed. (coleção guias da arquitetura no Rio de Janeiro), 2001, 162 p.

SCHERER, Regina M. D. Sistema municipal de ensino de Porto Alegre: da sua constituição às contribuições para as políticas públicas de educação no município. 2015. 175 f. Tese (Doutorado em Educação) - Universidade Federal do Rio Grande do Sul, Porto Alegre, 2015. Disponível em: https://lume.ufrgs.br/handle/10183/128902. Acesso em: Maio, 2018. 
SEGAWA, Hugo. Arquiteturas no Brasil 1900-1990. São Paulo: Editora da universidade de SP, acadêmica 21, 1997. 224 p.

SOUZA, J. P. C. Livro Denúncia. Porto Alegre: Editora Thurmann, Conferência realizada na Associação Brasileira de Educação, no Rio de Janeiro, em novembro de 1941, 2. ed. 1941.118 p.

VIANA, Alice O. A persistência dos rastros: manifestações do art déco na arquitetura de Florianópolis. Santa Catarina: UDESC, 2011. 323 p.

WERLE, Bibiana. A campanha de nacionalização e sua memória no alto do Taquari (RS). 2014. 178 f. Dissertação (Mestrado em História) - Universidade Federal do Rio Grande do Sul, IFCH, Porto Alegre, 2014. Disponível em: https://www.lume. ufrgs.br/handle/10183/88346. Acesso em: Maio, 2018.

20

\section{Publisher}

Universidade Federal de Goiás. Faculdade/Instituto/Escola. Programa de Pós-graduação Projeto e Cidade. Publicação no Portal de Periódicos UFG.

As ideias expressadas neste artigo são de responsabilidade de seus autores, não representando, necessariamente, a opinião dos editores ou da universidade.

RECEBIDO EM: 30/07/2020

APROVADO EM: 04/09/2020

PUBLICADO EM: 18/11/2020 